\title{
To improve tree support and the trash
}

\author{
Ge Zhang \\ School of North China Electric Power University, BaoDing 071000, China \\ Corresponding author
}

\begin{abstract}
This paper proposes a new simple tree with a fixed stent makes the transplant more safe and beautiful trees. The paper in order to put forward a new type of garbage can., mainly due to the improper waste disposal and litter bins filled leak, causing environmental pollution and cigarette butts caused by recycling the inconvenience.
\end{abstract}

KEYWORD: tree support; the trash

\section{INTRODUCTION}

In recent years, due to the increasing emphasis on the degree of green environment, the growing amount of trees growing, people on the survival rate of trees also increased accordingly. The application of the trees in the fixed stand plays a key role in ensuring the survival rate of the new trees. It can better prevent the trees from the external force and the resulting in the process of root growth is not strong. To facilitate the early extension of the tree roots into the implant and grow. Therefore, it has become a popular way to fix the trees with a fixed stand, especially in the process of urban greening, the garden construction sector has more choice to use a fixed stand for trees to be fixed. In many places, it is not a good way to deal with the fixation of trees. Some even find a few thick sticks fixed up a very large security hidden danger. This paper proposes a new simple tree with a fixed stent makes the transplant more safe and beautiful trees. The paper in order to put forward a new type of garbage can., mainly due to the improper waste disposal and litter bins filled leak, causing environmental pollution and cigarette butts caused by recycling the inconvenience.

\section{TREE SUPPORT IMPROVENT}

\subsection{Find the problem about tree support}

With the accelerated process of urbanization, people have a very high demand for urban greening. So the transplantation of trees are getting more and more frequent. Because the trees in the process of transplanting will inevitably cause some damage to the roots of the trees. Need to be fixed on the trunk to improve the survival rate of trees and to ensure that the tree's attitude is good. In the prior art, the fixed supporting rods are arranged symmetrically around the tree trunk. For example, a wooden rod body, the upper end of the fixed support is against a tree trunk, and nails are fixed on the tree trunk, and the lower end is propped against the soil. But in such a structure, the upper end of the fixed support is fixed with ordinary nails. The nails are thin, so it's very unstable. And when the construction, regardless of the first fixed or fixed lower part are not easy to fix, or barely on the right, but the support is too small for the tree trunk. And the serious point is too dangerous. On the road everywhere such as below this method of stabilization, with several sticks arbitrarily erected, and not about the appearance, said its security, if pedestrians accidentally touched one of the sticks, it will lead to deviation from the center, the risk can be seen everywhere.

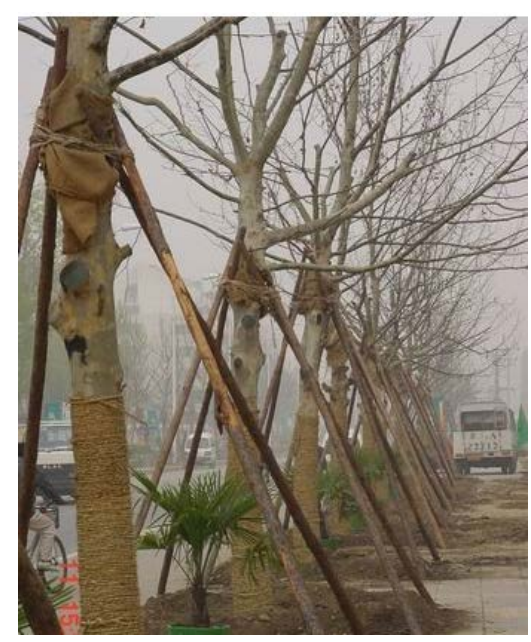


As is shown in the picture below, there are a lot of mature methods to fix it now. Such as fixed with "Jaws", improved two support and so on.

Fixed with "Jaws" is the most common way. The fixing bracket--improved two support is composed of a two pile support and a vertical column which is close to the tree body. Column and two columns supporting a horizontal pile cross first fastening nail, and then the steel wire rope tied, in cross and pile tree body pad protective bark. This support method is suitable for the central trunk more obvious, diameter at breast height in $\mathrm{cm} 3 \sim 6$ full crown tree or small tree planting.
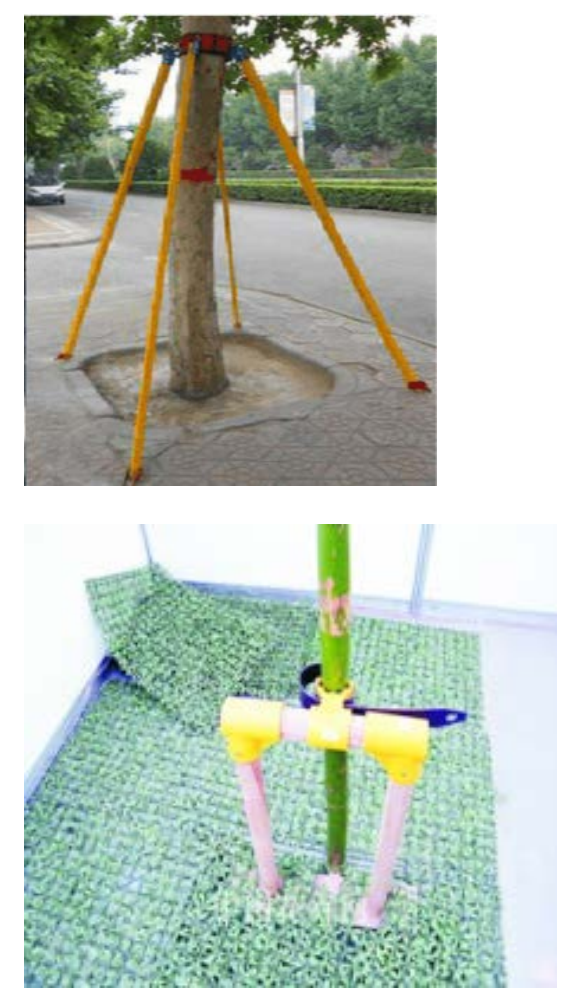

\subsection{Advantages of Support}

The bracket through the column support unit will hold trees to achieve the fixed effects on trees. Make a triangle frame. Choice of materials with hard mainly, in the main choice of iron, and the support of many other materials up very beautiful and of iron than the cheaper, only is not as secure as iron. Can be directly based on tree diameter at diameter size and height to some metal processing plant for processing and fixed inside the hoop rubber pad. The triangle fixing method under the tree has certain technical requirement, which must be fixed firmly and under the $2 / 3$ of the tree height. The fixing method can be used for drilling holes on the ground, and the triangular bracket and the ground are fixed on the floor. Play a stabilizing role. There is also a way is directly to the following a triangle on the ground and make it stable. When in use, trees planted after first of all to the roots of trees to soil compaction flattening, then carries on the simple assem- bly of fixed bracket. According to the actual need to select a certain number of fixed stent units placed around the trees. And the soft rubber block is contacted with the trees to prevent damage to the trees. The fixed bracket is fixed around the tree, and the fixed base is fixed on the ground by using the fixed rivet. The actual use of the process should pay attention to the whole bracket should be spray paint processing, reduce corrosion, fixed in the base with a fixed rivet should pay attention to avoid the rivet damage to the root of the trees. The novel fixing bracket is suitable for transplanting trees with large diameter at breast height, and is especially suitable for the fixation of trees on the main roads and sidewalks of the city.

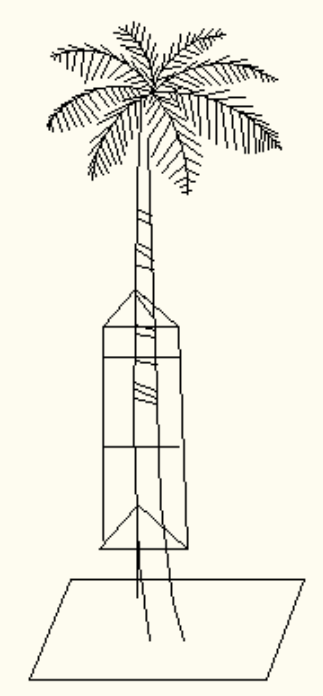

Its main advantages are the following.

(1) The trees formed surrounded by using fixed support unit, to overcome the traditional windproof support space, easy to cause injury and some drawbacks of the trees. (2) simple, and saving space.(3) the application of soft rubber block and the trunk in direct contact with the elastic soft rubber block can make lateral trees the swing has certain limits, guarantee the bark from harm, to ensure the normal growth of trees.(4) the use of lateral force triangle framework of the fixation under trees are in the wind of the uniform.(5) a complete set of fixtures can be connected to a lot of steel, which can be selected according to the actual situation. (6) flexibility and adaptability. (7) harmonious appearance, more suitable for use in the greening of urban roads, not only can save a lot of space on the sidewalk, and will not be as easy as the traditional fixed support to make pedestrians fall.

\subsection{Find the problem about the trash}

Every time after the garbage we can see its overflow. Everyone make a distance with it. The overflow of garbage caused a certain impact, some small garbage 
inclusion in the large garbage, making recycling difficult.

Garbage classification status in China: garbage has become a big problem of urban and rural environment, the relationship between urban and rural people's living, but also restricts the sustainable development of the city, do the work of garbage is for our country to realize the sustainable development of the urgent need.

Because China's urban garbage treatment has just started, there is a big difference in the composition of municipal solid waste. There are a series of problems such as

Processing technology and management tools are not perfect, resulting in a waste of practical and effective processing efficiency is low, processing capacity is far from the economic and social development needs and so on. How to combine the national conditions of our country, and adopt the suitable method of garbage classification, is the most pressing problem we face.

Analysis of the problem of recycling of discarded cigarette butts: cigarette butts can recycling, from discarded cigarette butts in the extraction of nicotine and acetate fibers can have new uses, cigarette butts recycling reuse technology can bring economic benefit, social benefit, ecological benefit.

Cigarette recycling is difficult to solve. The cigarette and also makes the presence of other Recyclable items difficult to recycle, this is the present situation of cigarette recycling issues.

\subsection{Improvement}

The top layer of the box cover can be opened freely, after opening, the second layer is a filter screen, so larger items not put into, smaller items such as cigarette butts can stored in such as is shown in the first region. The second a region of space utilization, the second part as a drawer, from the lid (from the front of the cover is mounted to the rear) from the rear to the rear in the second area, a spring fixed so that in its original length. Open the lid of the box, the spring is in a compressed state, second space pop up. When closing the box cover, second regional recovery. And two area filled, the spring will not make it pop.

Specific items selection methods and appearance: the specific spring choice, the need for a certain physical knowledge, the need to test the calculation, according to the material is different from the trash. First of all, we need to calculate the second space can contain up to the quality of goods, people in the most comfortable circumstances open bins to force, the friction coefficient of the space and the bottom. Space required length of the spring, according to the physical formula calculated spring stiffness coefficient, then select the spring. The filter mesh size should be in the cigarette length, the filter can be selected with the same diameter of the garbage box.
Appearance, such as the common plastic trash can be used to choose.

The working principle of the garbage bin: the spring can produce different force in the compression or extension, and the effect of the force on the object which is connected with it. Calculate the second space can contain up to the quality of goods, space and the bottom friction coefficient, and then choose required to remove the spring, under the anthropogenic (external force), the spring can be stretched or compressed function, then control the garbage box.
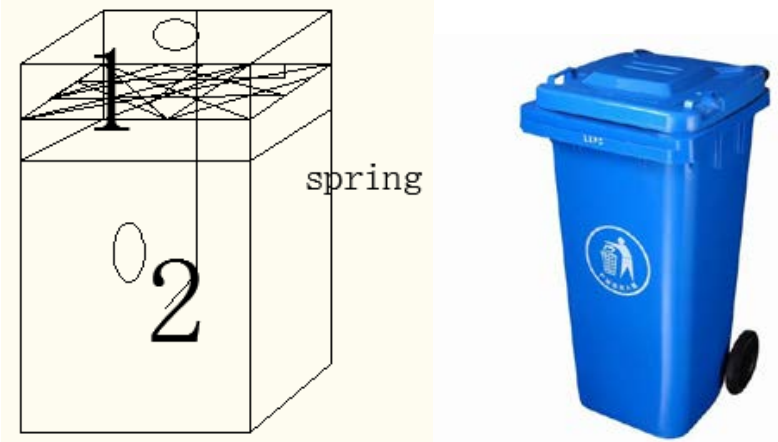

The design advantages of the analysis: when the second space is full, the elastic force cannot be opened, garbage will not overflow. The first space with separating net, big things cannot be put into, cigarette butts can separate from other items,. It's can be recycled.

Further assumption: the inside of the garbage can be divided into more space, with different stiffness coefficient of the spring is connected that can play the effect of garbage classification.

\section{SUMMARY}

This paper completed a small improvement in the real life of the two items. At first to see the trees on the streets above the stent placement is not reasonable, then thought of the two triangles into a stand, surrounded by trees in order to save space. The purpose is to provide a reliable and convenient transplanting tree fixing support for the purpose of preventing the trees from skew and dumping. The fixed supporting rod is characterized in that the upper part of the fixed supporting rod is connected with the fixed block, and the fixed block and the trunk are fixedly connected. The lower end of the fixed support is supported on the ground. The bracket includes a special nail and special nail comprises a nail rod and a nail rod end cap, cap comprises a tile shaped part and on the nail rod with anti rotation structure. The fixed supporting rod and the fixed block and / or fixed supporting rod and the ground by special screw connection, and the end of the fixed supporting rod arrived on the concave surface of the 
tile shaped parts of the cap. The trash city on both sides of the street are mainly for pedestrians discarded beverage bottles, cans, food packing box, paper bag, etc.. Although we can also be changed into a small number of small trash bins, in the case of unattended supervision, pedestrians will not be put into the garbage. Taking into account the garbage in the street on both sides of the small garbage can constitute the main pedestrian discarded food and beverage packaging, compared to the residential area of living garbage is simple and easy to deal with. After seeing the trash can full, it was hard to put the rubbish into the rubbish exposed, causing some damage to the environment, and some small debris cannot be recycled, but its impact on the efficiency of the recovery of large items. So it needs to be improved,

Only from the principle of speaking, If we want to make it out, there is a certain requirement with technical.

\section{ACKNOWLEDGMENTS}

The writing of this paper is challenging. I want to take this chance to thanks to my teacher----Mr. Ming. In the process of composing this paper, he gives me many academic and constructive advices, and helps me to correct my paper. Last but not least, I'd like to thank all my friends, especially my five lovely roommates, for their encouragement and support. The rush of time and the lack of professional level of the whole paper certainly have not yet found the shortcomings and mistakes. I am very grateful to the teachers and students who point out the problems.

\section{REFERENCES}

[1] Information on:

https://www.baidu.com/link?url=CTphgohGyIxh4QQyuKS3j

KD9wrADtWmUDa-

nWIIdkwamKRpj4kbHRLdLL4escn2DujJ6EUsIpR6ygS9w9

3-Z8K\&wd=\&eqid=fa5e7c0e00061eab00000002576f6522

[2] Information on:

http://www.docin.com/p-725664104.html

[3] Information on:

http://wenku.baidu.com/link?url=7griJ2Y0RepcQYb1As220

PMu6PwA8MtGw5tuoAdSlKav0rPGPavKVKxNlMT55uG9

9EiQSdQw-N0LUXo66yF6DQpDIFi8qcL08Jdt0ThgaTq

[4] Information on: http://www.X-jishu.com/zhuanli/01/201220707802.html

[5] Information on:

http://news.china-

flower.com/paper/papernewsinfo.asp?n_id=222660 